\title{
La revalorización ontológica de la obra en las vanguardias: algunos apuntes teóricos ${ }^{1}$
}

\author{
Víctor Manuel Osorno Maldonado \\ Universidad Nacional Autónoma de México
}

\begin{abstract}
Resumen
En este artículo se propone que el surgimiento de las vanguardias europeas constituye no sólo una transformación estilística, sino un cambio en la estructura esencial de las artes, es decir, una revalorización de la ontología inherente al quehacer estético. Para sustentar este planteamiento, el autor acude a reflexiones de algunos teóricos y filósofos como Renato Poggioli, Peter Bürger, Hans
\end{abstract}

${ }^{1}$ Si bien el término "ontología" se asocia con una larga y compleja tradición filosófica — que inicia con la Metafísica de Aristóteles, extendiéndose hasta el pensamiento de filósofos como Husserl, Heidegger y Hartmann-, las siguientes reflexiones en absoluto pretenden ofrecer una panorama analítico sobre el origen y las implicaciones de dicha noción metafísica, menos aún articular un análisis ontológico de la estética vanguardista. En este trabajo, la palabra "ontología” y sus derivados sólo se utilizan para designar aquello relativo al ser o esencia de los entes y fenómenos. En el caso del arte literario, la transformación que sufren las estructuras y los contenidos durante el vanguardismo afectó no sólo el resultado formal de la obra, sino las concepciones que de ella se tenía y las posibilidades de su realización. Desde esta perspectiva, y considerando la magnitud de las transformaciones estéticas que supone el vanguardismo, parece que el término "ontológico (-a)" describe adecuadamente este tipo de cambio que no sólo tiene que ver con lo externo sino con lo profundo, es decir, con el nuevo sentido que la literatura adquiere después de las vanguardias. 
Magnus Enzensberger, Ortega y Gasset, entre otros, al tiempo que encuentra en varias características del arte de vanguardia, por ejemplo, el ensimismamiento, la paradoja, el humor, la fragmentariedad y el shock, argumentos sólidos para explicar por qué la literatura y las artes modificaron su ser esencial durante las primeras décadas del siglo XX. A manera de colofón, se menciona cómo esta serie de innovaciones de la vanguardia europea encuentran resonancia en algunas obras latinoamericanas, no pasando por alto el problema que implica el fenómeno de la transculturación.

Palabras clave: vanguardia, ontología, literatura, transformación, crisis mimética.

\section{Abstract}

In this article it is proposed that the emergence of the European avant-garde is not only a stylistic change, but a change in the essential structure of the arts, that is, an appreciation of the ontology inherent aesthetic work. To support this approach, the author turns to thoughts of some theorists and philosophers as Renato Poggioli, Peter Bürger, Hans Magnus Enzensberger, Ortega y Gasset, among others, while he finds in several avant-garde features, for example, the absorption, the paradox, the humour, the fragmentation and shock, solid arguments to explain why literature and the arts modified essential being during the first decades of the twentieth century. As a coda, is mentioned how this series of European avant-garde innovations found resonance in some Latin American works, not ignoring the problem involving the phenomenon of acculturation.

Keywords: Avant-Garde, Ontology, Literature, Transformation, Mimetic crisis.
A 1 analizar cualquier obra literaria, sin importar la perspectiva - 1 crítica que se adopte, es necesario trazar una línea del tiempo que permita ubicar al texto en un contexto específico. Se trate de la lírica griega, de la novela de caballerías o del cuento fantástico, 
el sentido de las obras resulta más amplio cuando se conocen algunos hechos que ocurrían en el mundo externo a éstas. Pero además de contar con un telón de fondo nítido y detallado en cuanto a la historia, la cultura y la sociedad, situar un discurso literario en un momento determinado permite comprender mejor el porqué de las formas y los contenidos; observar cómo varían las modas o tendencias del arte a partir de la relación que los creadores establecen con su entorno y con tradiciones anteriores. Desde este punto de vista, aunque el vínculo entre lo estético y lo real resulta innegable, es cierto que los procedimientos para establecer dicho contacto han variado con el discurrir de la historia, pues la literatura se transforma por arte y capricho de aquellos que la inventan. Cambia el mundo y con ello el estilo, la estructura y la intención de los discursos que lo describen desde el terreno del arte.

Con frecuencia, la historia de la literatura es asumida como un fenómeno dialéctico, y con cortes temporales precisos, en el que el surgimiento de una corriente responde al rechazo de los procedimientos estéticos que la tradición anterior había desarrollado. Sin embargo, la transformación de la serie literaria es un proceso mucho más complejo, ya que los autores, además de oponerse a lo establecido y buscar la novedad, retoman ciertos temas, formas e intereses de la literatura que les antecede para reformularlos. Sólo así es posible la gestación de nuevas concepciones en torno al arte literario, ya que en ningún caso lo novedoso nace de la ignorancia u olvido del pasado, sino de su reconsideración. No hay escritor que se enfrente a la tabula rasa ni corriente literaria que nazca por generación espontánea; tampoco existe un libro aislado y de originalidad absoluta. Entonces, los cambios que experimenta la literatura, más allá de ajustarse a la secuencialidad histórica, se muestran como una red de sentido que a su paso atrapa resabios del pasado; como un devenir que, a través de los textos, interconecta diferentes espacios, tiempos, experiencias y realidades. Hans 
Magnus Enzensberger, en su ensayo "Las aporías de la vanguardia” (1963), afirma que: "no es sólo trillada, sino ahistórica la fe ciega que se complacen en depositar en el gastado concepto de generación, como si la vida de las artes, y no la de las triquinas, fuese la sujeta a la ley biológica de la sucesión de las generaciones, o como si la substancia de un himno de Hölderlin o de una pieza de Beckett quedase determinada por el "año» del autor" (1963: 2). Lo que marca la transformación entre un estadio y otro es el signo de la crisis.

Pero aunque el decaimiento de los mecanismos discursivos, o mejor aún su estandarización, es una constante en el proceso de evolución literaria, existen algunos momentos en los que la tendencia iconoclasta resulta más contundente. Prueba de ello es la transición del siglo XIX al XX, periodo en el que varios creadores europeos, cansados de que el arte fuera un reflejo en cierta medida fiel de la realidad, empiezan a experimentar con sus respectivos materiales: la palabra, la forma, el color, el sonido y el movimiento. Hasta entonces, la transformación de las obras estéticas se llevaba a acabo de manera más superficial que profunda pues, desde el clasicismo grecolatino hasta la primera etapa del romanticismo, se mantuvo una estructura esencial a las artes que consistía en la representación del mundo, en la imitación y la deformación de lo observado por el hombre. Cuando los artistas desafían estos mecanismos discursivos e intentan con su trabajo no sólo re-describir sino agregar algo a la realidad, dicha estructura tradicional ${ }^{2}$ se frag-

${ }^{2}$ Por tradicional se entiende aquellas obras y corrientes artísticas cuyas técnicas y mecanismos de representación no desafían el significado preestablecido del lenguaje, la configuración de modelos genéricos y, en algunos casos, las leyes de causa y efecto con que la ciencia explica el modus operandi del mundo. Sin adentrarse en precisiones que desviarían el objetivo de este trabajo, podría decirse que en el arte y la literatura tradicionales el lenguaje se constrińe a la razón $y$ ofrece al receptor un mensaje concreto, mientras que las manifestaciones van- 
menta y la creación estética se abre a nuevas posibilidades que ya no están anquilosadas en el mundo real.

Poetas y pintores, principalmente, se van haciendo conscientes de su libertad expresiva ante el espacio en blanco y de las incomodidades que esto genera, ya que los receptores estaban acostumbrados a que todo en el arte debía tener una explicación racional y un claro eco en la realidad. Al respecto, Mario de Micheli, en su estudio Las vanguardias artísticas del siglo XX (1984), refiere una nota periodística, aparecida en el National el 18 de marzo de 1838, en la que Alexandre Decamps — pintor que destacó junto a Delacroix y Vernet dentro de la escuela romántica francesa-, describe con claridad el rechazo de la burguesía ante las nuevas inclinaciones estéticas, recepción que se mantendría hasta el estallido y auge del vanguardismo:

las obras de arte de una originalidad demasiado independiente o de una ejecución demasiado audaz ofenden la vista de nuestra sociedad burguesa, cuyo limitado espíritu no puede abrazar ni las vastas concepciones del genio ni los arrebatos generosos de amor a la humanidad. El vuelo de la opinión es de corto alcance; todo lo que sea demasiado vasto, todo lo que se eleve por encima de ella se le escapa (19).

A partir de este comentario de Decamps, es posible observar que la literatura cambia de función respecto a la sociedad, debido a que las obras ya no son la expresión de los valores imperantes en el espacio extraliterario, sino un discurso que se opone a ellos mostrando las carencias, las limitaciones y los prejuicios que, por parte de creadores y receptores, hacían del arte un procedimiento reproductivo. A decir de Jochen Schulte-Sasse, en su texto "La vanguardia

guardistas se concentran en desmantelar los significados y las formas que, sin cuestionamiento alguno, se adjudicaban al lenguaje y las artes. 
artística" (1989), esta oposición explícita entre el arte y la sociedad inicia su desarrollo en el siglo XIX, ya que "Desde el romanticismo en adelante, con algunas pocas excepciones como el realismo decimonónico, el impulso del arte culto ha sido su relación antagónica, en forma y contenido, con la sociedad" (1989: 546). Pero dicha confrontación, aunque gestada en el romanticismo, eclosionaría de manera absoluta durante las tres primeras décadas del siglo XX, lapso en el que se sitúa el nacimiento del vanguardismo europeo. ${ }^{3}$

Esta falta de correspondencia entre arte y realidad acarrea múltiples consecuencias que se manifiestan tanto en el estilo como en la estructura de las obras, es decir, en el plano superficial pero también en el profundo, pues las vanguardias no sólo suponen una ruptura formal sino un cambio de concepción respecto al ser, la esencia y el sentido de las artes. En cuanto a la literatura, de todas las transformaciones que sufrió dicho proceso creativo conviene anotar dos fenómenos complementarios y fundamentales para la revalorización ontológica de la obra literaria que se lleva a cabo durante las vanguardias: por un lado, la tendencia del arte a ensimismarse y reflexionar sobre sus limitaciones y alcances; por otro, el declive de la realidad humana como principal asidero para la decodificación de las obras.

${ }^{3}$ Los antecedentes inmediatos a este periodo del arte son mucho más vastos y complejos, por lo que merecen un estudio aparte. Aquí, las referencias a la estética decimonónica, aunque muy generales, tienen la finalidad de establecer un punto de partida para la reflexión sobre las innovaciones vanguardistas. Sin duda, la consideración del esteticismo y del decadentismo francés, por mencionar dos corrientes cercanas a las vanguardias, evidenciaría más aspectos fundamentales en la transformación que la obra artística sufre durante dicha época. Sin embargo, un estudio histórico de esa naturaleza rebasa los intereses del presente trabajo. 
Respecto a la manifestación del primer fenómeno, Xavier Rubert de Ventós, en su estudio El arte ensimismado (1963), ${ }^{4}$ menciona que "La novela, al igual que la pintura, tendió a afirmarse entonces como creación pura, no como expresión de lo real sino como nueva figuración [...]. La obra literaria apuntaría hacia sí misma y nada más; sería, como decía Lapicque de la nueva pintura, «signo y símbolo de sí misma»" (1963: 86). Tal retracción del discurso permite que autores y lectores se detengan a pensar en la palabra y su deformación estética, pues la literatura cada vez remite menos al afuera y más a las implicaciones que conlleva su proceso constructivo, de manera que, como apunta Schulte-Sasse "El contenido social del arte comienza ser sustituido por el contenido predilecto de reflexionar sobre su forma" (1989: 547). Por otro lado, Helio Piñón, en el "Prólogo" a Teoría de la Vanguardia (1974), estudio de Peter Bürger que constituye una referencia medular en este tema, afirma que "la consciencia lingüística de la realidad compromete al vanguardista en la reflexión sobre el lenguaje como vía de acceso a realidades nuevas: el lenguaje, pues, construye la realidad, no refiere un mundo preexistente" (1987: 13). Se hace explícito el poder creador de la palabra y la literatura se libera de ataduras; los autores ya no describen el mundo, lo erigen; ya no hay géneros literarios, sólo escritura artística en el más amplio y libre de los sentidos; ya no hay obras terminadas, sino apuntes y esbozos que permiten al lector observar el andamiaje poético o narrativo que, hasta entonces, permanecía siempre oculto. Cuando el arte literario se cierra para el mundo, las palabras se ensimisman provocando que el ob-

${ }^{4}$ Aunque dicho análisis contiene varias referencias al nouveau roman, movimiento literario francés surgido en la década de los sesenta y liderado por Robbe-Grillet, Michel Butor y Nathalie Sarraute, el autor también refiere, y con igual grado de importancia, obras y autores vanguardistas como Marinetti, Dalí, Joyce, Duchamp, de manera que sus comentarios, aunque no se encasillan en el periodo de las vanguardias, resultan muy útiles para el análisis de las mismas. 
jeto estético muestre sus entrańas y se reafirme como artificio. ${ }^{5} \mathrm{Si}$ bien, antes del nacimiento de las vanguardias europeas la literatura ya daba muestras de este carácter especular y hermético, es hasta inicios del siglo XX cuando un sinnúmero de autores radicalizan dichos rasgos y hacen de su escritura una caja de espejos.

Otro factor decisivo para la reformulación de la obra que tuvo lugar durante las vanguardias, consiste en lo que Ortega y Gasset denominó "La deshumanización del arte" (1925), ensayo en el que afirma que: "Si el arte nuevo no es inteligible para todo el mundo, quiere decirse que sus resortes no son los genéricamente humanos. No es un arte para los hombres en general, sino para una clase muy particular de hombres que podrán no valer más que los otros pero que evidentemente son distintos" (1995: 319). De esta forma el autor explica que los nuevos productos estéticos —entendiendo por ello el arte de vanguardia-, se caracterizan por alejarse de los intereses humanos en busca de una pureza estética; es decir, de una autorreferencialidad que se pretende absoluta pero que sólo puede ser parcial, ya que, siguiendo nuevamente a Ortega y Gasset, "Aunque sea imposible un arte puro, no hay duda alguna de que cabe una tendencia a la purificación del arte. Esta tendencia llevará a una eliminación progresiva de los elementos humanos,

${ }^{5}$ En 1917 Víktor Shklovski, perteneciente a la escuela formalista rusa, publica uno de sus textos paradigmáticos: "El arte como artificio", cuyo planteamiento central postula que la esencia de las obras artísticas consiste, precisamente, en aparecer ante el receptor como objetos imaginarios e incompletos, discursos irreales y extrańos cuyo valor reside en su naturaleza estética y en su organización como artificios del lenguaje y del pensamiento. "La finalidad del arte es dar una sensación del objeto como visión y no como reconocimiento; los procedimientos del arte son el de la singularización de los objetos, y el que consiste en oscurecer la forma, en aumentar la dificultad y la duración de la percepción. El acto de percepción es en arte un fin en sí y debe ser prolongado. El arte es un medio de experimentar el devenir del objeto: lo que ya está "realizado» no interesa para el arte" (2007: 60). 
demasiado humanos, que dominaban en la producción romántica y naturalista" (321). El hecho de que los rasgos de humanidad sean cada vez más opacos, constituye un requisito indispensable para la introyección del arte en sí mismo, para la evasión y rechazo de la realidad, para la verdadera expresión de los genios creativos porque, tal y como se afirma en el texto comentado, "Es fácil decir o pintar una cosa que carezca por completo de sentido, que sea ininteligible o nula: bastará con enfilar palabras sin nexo, o trazar rayas al azar. Pero lograr construir algo que no sea copia de lo «natural», y que, sin embargo, posea alguna sustantividad, implica el don más sublime" (328).

Una vez planteados el ensimismamiento y la deshumanización como elementos medulares en la idea vanguardista del arte y la literatura, conviene seguir trazando una ruta de comprensión que, a partir de la filosofía y la teoría literaria, permita observar las diferentes perspectivas desde las que se ha estudiado la estética general de las vanguardias. Al respecto, Rodolfo Mata, en su "Prólogo" a Teoría del arte de vanguardia (1962), estudio pionero de Renato Poggioli, considera que los análisis del fenómeno vanguardista pueden agruparse en dos vertientes claramente identificables:

se asocia el primer eje con las respuestas a los cuestionamientos sobre el lugar de las vanguardias en la sociedad y sus relaciones e interacciones con ella en el sentido más amplio. El segundo eje se puede perfilar como el que inquiere por el lugar de las vanguardias dentro de la propia institución del arte. El primer eje está vinculado mayormente con la historia, mientras el segundo puede producir reflexiones y conceptos cuya aplicación sea transhistórica. Así, desde aquél, las vanguardias de las primeras tres décadas del siglo XX, hoy llamadas "históricas", son algo totalmente distinto de las llamadas "neovanguardias" de los años cincuenta y sesenta, en tanto desde el segundo, tendrán importantes rasgos en común. (1962: III). 
Más adelante, Mata afirma que Teoría de la vanguardia de Peter Bürger se ubica dentro de la primera perspectiva, aquella preocupada por los cambios que el arte sufrió en tanto institución de la sociedad burguesa y también respecto a los medios de producción, distribución y recepción, por acotar algunos de los aspectos en los que se centra dicha propuesta de corte sociológico. Por otro lado, Rodolfo Mata considera que un modelo de análisis como el articulado por Poggioli permite trascender, hasta donde sea pertinente, límites temporales y asumir la vanguardia como un fenómeno que, si bien está determinado históricamente, se infiltra de diversas formas en el arte posterior. Lo que aquí interesa, es retomar el trabajo de ambos teóricos de la vanguardia (Poggioli y Bürger) y, más que confrontar sus puntos de vista, estudiar cómo cada uno explica las profundas variaciones que la noción "obra de arte" experimentó en el contexto del vanguardismo europeo. Pero además de describir las alteraciones formales que trajo consigo el arte vanguardista, los modelos de Poggioli y Bürger ofrecen diversas reflexiones tocantes a la estructura esencial de los discursos estéticos, por lo que resulta factible profundizar, a partir de sus propuestas, en lo que aquí se denomina como la revalorización ontológica de las obras literarias.

Aunque parece un tanto obvio señalar que el interés por "lo novedoso" es piedra de toque en los movimientos vanguardistas, e incluso una actitud que aparece y reaparece en cada periodo del arte, Renato Poggioli establece algunos matices que en dicho contexto recibe la idea de lo nuevo. Para el crítico italiano, las vanguardias representan un hito en el desarrollo de la estética occidental porque "se trata de una novedad no de forma sino de sustancia, un fenómeno verdaderamente excepcional en la historia de la cultura" (1962: 29). Sin embargo, y volviendo al planteamiento inicial de que la evolución literaria, más que una secuencia de periodos muy bien definidos, funciona a la manera de un devenir, Poggioli 
afirma que el interés por lo novedoso y por la experimentación con el material creativo, si bien es característico del vanguardismo, cuenta con una estirpe romántica, ya que:

Uno de los aspectos más importantes de la poética práctica de las vanguardias es aquel al cual se alude con el término de experimentalismo. A este respecto es fácil reconocer el precedente inmediato de la experimentación estética romántica, la ansiosa búsqueda de formas nuevas y vírgenes, tendiente no sólo destruir el sólido reticulado de las reglas, o la jaula dorada de la poética clásica, sino también a buscar una nueva morfología artística, un nuevo lenguaje del espíritu (69).

Esa búsqueda romántica de novedad formal es el caldo de cultivo que permitiría una mutación mucho más compleja y profunda durante las primeras décadas del siglo XX, momento en el que, además de renovarse las estrategias de representación, el quehacer artístico en su totalidad adquiere un nuevo sentido: los creadores cuentan con la libertad necesaria para romper cualquier molde, las obras no se articulan a partir de un sentido lógico-causal, apelan más a la intuición que a la razón, y los receptores se inquietan porque, a pesar de reconocer su mundo en los discursos artísticos, éste funciona bajo otras leyes que nada o poco tienen que ver con las de la naturaleza. Entonces, como explica Helio Piñón, "La idea de sistema, esencial en el arte clásico, se invierte en la vanguardia en la medida que no se trata de organizar canónicamente realidades existentes, sino de provocar la emergencia de realidades implícitas" (1987: 9). Por tanto, la puesta en crisis del sistema jerárquico que articulaba la expresión artística representa uno de los aspectos, quizá el más relevante, que interviene en la transformación ontológica de las obras vanguardistas.

Es cierto que por más experimental que sea un discurso siempre debe contar con un andamiaje que lo soporte, con determinados 
rasgos de unidad que lo doten de sentido, aunque éste sea oscuro, simbólico, iconoclasta, paródico y/o disperso. Al no poder obviar dicha necesidad de organización, inherente a cualquier objeto estético, lo que desafían los vanguardistas es la concepción de la obra como una entidad estratificada, como una estructura unilateral en la que las partes se organizan en función de un concepto global. Entonces, y siguiendo los planteamientos de Peter Bürger, "La obra de vanguardia no niega la unidad en general (aunque incluso eso intentaron los dadaístas), sino un determinado tipo de unidad, la conexión entre la parte y el todo característica de las obras de arte orgánicas" (1987: 112). De esta forma, se desploma el carácter monolítico con que hasta entonces se concebía el arte porque, según los planteamientos de Bürger, a diferencia del artista clásico, "El vanguardista, por su parte, reúne fragmentos con la intención de fijar un sentido (con lo cual el sentido podría ser muy bien la advertencia de que ya no hay ningún sentido). La obra ya no es producida como un todo orgánico, sino montada sobre fragmentos"(133). Así, el quiebre del todo y la subsecuente dispersión de las partes, mismas que esperan ser reacomodadas de otro modo y adquirir un significado distinto, también constituyen aspectos fundamentales en la revalorización del arte y la literatura que aquí se describe.

Si se piensa que, desde la antigüedad hasta nuestros días, los materiales con los que cuenta el artista son los mismos, lo que ha variado entonces es la actitud que se asume frente a ellos, tanto en el proceso de creación como en el de recepción. En este sentido, Bürger apunta las diferentes posturas adoptadas por el arte orgánico, es decir, tradicional, y el arte inorgánico, o de vanguardia, dejando claro que ciertas variaciones, aunque de carácter técnico y formal, cuentan con una repercusión importante en el proceso de evolución ontológica de las obras, ya que: 
El artista que produce una obra orgánica (lo llamaremos en lo sucesivo clasicista, sin querer dar por ello un concepto del arte clásico), maneja su material como algo vivo, respetando su significado aparecido en cada situación concreta de la vida. Para el vanguardista, al contrario, el material sólo es material; su actividad no consiste principalmente en otra cosa más que en acabar con la "vida" de los materiales, arrancándolos del contexto donde realizan su función y reciben su significado. El clasicista ve en el material al portador de un significado y lo aprecia por ello, pero el vanguardista sólo distingue un signo vacío, pues él es el único con derecho a atribuir un significado. De este modo, el clasicista maneja su material como una totalidad, mientras que el vanguardista separa el suyo de la totalidad de la vida, lo aísla, lo fragmenta. (1987: 132-133).

Antes de las vanguardias, la creatividad del artista se reducía, en cierta medida, a combinar de formas distintas una serie de materiales previamente codificados; por ejemplo, en el plano de la literatura, los géneros, los temas y la intención de los discursos contaban con una fuerte carga semántica establecida por la tradición y por los intereses sociales del momento, de manera que los escritores tomaban dichas piezas para construir, dando muestras de su propio estilo, un discurso bien acabado que tuviera evidentes reminiscencias con el mundo extraliterario. Pero como señala Bürger, el surgimiento de obras inorgánicas supone la fragmentación tanto de la estructura como del significado con que contaban cada parte del discurso estético, de ahí que dicho teórico se refiera al "signo vacío" como punto de partida y destino de la expresión vanguardista. Tal libertad sólo pudo alcanzarse mediante la descontextualización de la materia prima con que se construían las obras, fenómeno que la escuela formalista rusa, concretamente Víktor Shklovski, había denominado "extrañamiento" y que, a decir de Bürger, se radicalizaría durante las vanguardias provocando un shock en los receptores, pues: 
Cuando los formalistas rusos hacen del "extrañamiento" el procedimiento artístico, el conocimiento de la generalidad de esta categoría permite que en los movimientos históricos de vanguardia el shock de los receptores se convierta en un principio supremo de la intención artística. El extrañamiento efectivo se convierte, de esta manera, en el procedimiento artístico dominante y puede al mismo tiempo ser distinguido como categoría general. Esto no quiere decir que los formalistas rusos hayan mostrado el extrañamiento en el arte vanguardista (al contrario, el Don Quijote y el Tristam Shandy son las pruebas preferidas por Sklovkij); solamente afirmo que hay una conexión necesaria entre el principio de shock en el arte de vanguardia y el estudio de la validez de la categoría general de extrañamiento (56-57).

Respecto a las artes plásticas, basta con pensar en la rueda de bicicleta empotrada en un banco que Marcel Duchamp presentó en 1915, creando con ello la técnica del ready-made, expresión más característica del dadaísmo y que consiste en apartar de su contexto objetos de uso cotidiano para presentarlos como obras de arte. Posteriormente, Duchamp se valdría de un urinario y un escurridor de botellas para desconcertar al público con otras dos obras de vanguardia que radicalizan el extrañamiento en shock. En este punto, no es fortuito aludir a uno de los máximos exponentes del dadaísmo para ejemplificar el shock que genera el arte vanguardista, ya que dicho movimiento se caracterizó por la radicalidad, la rebeldía, la mofa ante lo solemne y la instauración del absurdo como mecanismo primordial que revierte la función y el significado del arte. Para ejemplificar el shock en las expresiones literarias, sólo hay que recordar el primer manifiesto dadaísta de 1918, en el que Tristán Tzara escribiría: "Libertad: DADA, DADA, DADA, aullido de colores encrespados, encuentro de todos los contrarios y de todas las contradicciones, de todo motivo grotesco, de toda incoherencia: LA VIDA" (De Micheli, 1984: 302), o algún pasaje 
de la novela Nadja, escrita por André Breton en 1928 y que se convertiría en un texto ejemplar de lo que los surrealistas denominaron "escritura automática". ${ }^{6}$

En un ambiente cargado de novedad y en el que se privilegiaba el individualismo, el shock provocado por las obras vanguardistas dio origen a las más diversas opiniones. Mientras que un sector de los receptores rechazaron dichas manifestaciones estéticas, tildándolas de incomprensibles y revelando con ello su nula capacidad para aceptar algo que superara la racionalidad, también hubo quienes se mostraron abiertos a una nueva forma de interpretar el arte. Ahora el reto consistía en hallar un posible sentido sin pretender con ello englobar la obra en un concepto específico, ya que la fragmentariedad de los discursos y el privilegio de las partes, principio creativo de las vanguardias, también se convirtió en fundamento de la recepción. Con el cambio ontológico de la obra que ocurre durante este periodo del arte, los intérpretes también se liberan de la razón como punto de arranque y puerto de sus pensamientos, pues el hecho de descifrar una obra vanguardista ya no requiere únicamente de una labor exegética, sino de un tipo de lectura que respete el hermetismo, la deformación y lo que de inexplicable queda en las obras. Justo cuando no se quiere aprehender de ma-

${ }^{6}$ Desde sus orígenes, dicho procedimiento literario ha contado con adherentes y detractores, pues algunos filósofos y críticos, por ejemplo Ortega y Gasset en su ensayo citado, consideran que la escritura automática carece de valor estético porque está fundada sobre el sinsentido y no cuenta con una finalidad o intención delineadas. Por otra parte, hay quienes observan en este tipo de manifestaciones vanguardistas el deseo de alejar al lenguaje y las artes de imposiciones lógicas, ya que, como escribe Maurice Blanchot en La parte del fuego (1949), "La escritura automática es una máquina de guerra contra la reflexión y el lenguaje. Está destinada a humillar el orgullo humano, particularmente bajo la forma que le ha dado la cultura tradicional. Pero, en realidad, ella misma es una aspiración orgullosa a un modo de conocimiento, y le abre a las palabras un nuevo crédito ilimitado" (2007: 84). 
nera absoluta lo que el artista "quiso" decir en su discurso, es el momento en que la interpretación se transforma en acto creativo, permitiendo que la mirada matice un cuadro o escriba una historia. $\mathrm{Al}$ respecto, Renato Poggioli considera que:

a pesar de todo la oscuridad del arte de vanguardia no se resuelve solamente con el concurso de la exégesis. Esta última, que nunca es absolutamente necesaria cuando el lector o espectador está bien preparado y dispuesto, nunca es suficiente cuando el lector o espectador es incapaz de superar una innata antipatía. Sin negar la eficacia de la educación y del hábito, la oscuridad del arte moderno seguirá siendo obstáculo insuperable para quien conscientemente niegue su asentimiento, aunque sea provisorio, mientras que para quien esté dispuesto a aceptarlo aunque sólo sea en principio las más arduas esperanzas serán obstáculos superables, las obras más refractarias al entendimiento se le harán accesibles. La interpretación del arte de vanguardia es, pues, esencialmente problema no exegético, sino psicológico (2011: 161-162).

Aunque resulta innegable que la exégesis es consustancial a la decodificación de cualquier discurso, Renato Poggioli la rechaza como medio de acercamiento a las obras de vanguardia porque, hasta entonces, dicho ejercicio interpretativo estaba domeñado a la comprensión lógico-causal de los elementos que integran la expresión artística y literaria. Una vez experimentado el shock ante las obras de vanguardia, los receptores se vieron obligados a abandonar sus viejos procedimientos de interpretación, hecho que les permitió comprender que la riqueza y profundidad de ese tipo de arte reside en el desafío de lo racional, en su aspecto inacabado, en lo inasible de sus formas y en lo inexplicable de sus planteamientos. Ante artificios de esta naturaleza, el exégeta tradicional no es capaz de cuestionar la constitución del discurso, ni de responder las inquietudes derivadas de su experiencia estética, pues su forma de decodificar las obras se contrapone a la manera en que éstas sugieren ser leídas. 
Así, el lector y el crítico vanguardistas se vieron comprometidos a ser tan originales y arriesgados como lo fueron los artistas. Pero algunos no pudieron lograrlo, debido a la dificultad que supone adoptar una postura abierta ante algo tan novedoso y desconcertante, actitud que Poggioli identifica con un problema más psicológico que hermenéutico.

Otro aspecto primordial en la nueva concepción de las obras vanguardistas, consiste en la importancia que cobró el humorismo como herramienta de crítica artística, científica y social. Es cierto que la ironía y la parodia son dos facetas del humor que cuentan con una presencia constante en la tradición artística, de manera particular en la literaria, ya que, desde los griegos hasta los románticos, la risa siempre estuvo acompañada de fuertes críticas ante instituciones sociales, políticas y religiosas. El vanguardismo continúa con esa tradición de presentar un asunto serio por medio de la carcajada, de observar los malestares del mundo y comunicarlos con la estridencia de la risa; sin embargo, el humor de los vanguardistas también se dirige, y con una fuerza especial, a la institución del arte, al lugar que ocupa el artista en la sociedad, a la importancia de su trabajo y a las pretensiones que todo creador deposita en su obra. Por tanto, con el humorismo vanguardista, aunado a la tendencia del ensimismamiento presente en todas las manifestaciones estéticas, se alcanza aquello que Bürger denomina "la autocrítica del subsistema social artístico” (1987: 69), momento en el que los autores privilegian el autoescarnio, la mofa, el sarcasmo, lo grotesco y la caricatura, por mencionar algunas directrices del quehacer crítico-estético que se desarrolló a lo largo de este periodo. En el arte de vanguardia, la risa es un recurso casi obligado y una de las vertientes mayormente explotadas fue la del humorismo crítico del progreso científico, pues cabe recordar que a principios del siglo XX el despunte tecnológico fue tal que, en varios facetas 
de la vida, la máquina empezó a sustituir al hombre. En relación con dicho aspecto, Poggioli apunta que

Una de las formas dominantes o peculiares del humorismo anticientífico es la del humor negro o bilis negra, por usar un epíteto caro a André Bretón [...]. Un humorismo de este tipo, patético, grotesco y absurdo, predilecto de algunas corrientes vanguardistas [...] obra pues, ante todo, sobre el mecanismo formal de la vida moderna, de la cual se sirve, según la consabida paradoja de lo cómico, con el fin de aniquilarlo y agotarlo (2011: 151).

Dicho mecanismo formal de la vida moderna, a pesar de que constituye el punto de ataque del vanguardismo, es también responsable del cambio ontológico que hubo en la estructura de las obras, pues al tiempo que progresaba la ciencia y el saber sobre el mundo, lo hacían el arte y la filosofía. Con las vanguardias el discurso se manifiesta autocrítico y encuentra en dicha postura gran parte de su ironía y su modernidad, ya que, como apunta Octavio Paz en Los hijos del limo (1974), "Lo que distingue a nuestra modernidad de la de otras épocas no es la celebración de lo nuevo y sorprendente, aunque también eso cuente, sino el ser una ruptura: crítica del pasado inmediato, interrupción de la continuidad. El arte moderno no sólo es el hijo de la edad crítica sino que también es el crítico de sí mismo" (1974: 335). Como era imposible sustraerse a dicho devenir modernizante, el artista de vanguardia optó por burlarse de la realidad y de sí mismo, postura que podría explicar el auge que, en el caso de la literatura, adquiere la imagen del escritor como un ser trashumante, opaco, fracasado, anónimo. Además de la paradoja implícita en el humor, las formas en que los vanguardistas se valieron de él multiplicaron las contradicciones al interior de las obras: los libros, los cuadros, los personajes y las historias no estaban completos; el mundo erigido en los discursos era muy extrańo, parecía que todo se había convertido en carnaval: lo real, 
ficticio; lo solemne, irrisorio; lo defectuoso, perfecto; los apuntes, la obra; el receptor, creador. Después del desconcierto y la risa, se puede vislumbrar que el ensamblaje paradójico de las obras fue otro de los aspectos que coadyuvó a revalorizar su ontología.

Entre 1928 y 1929, René Magritte pinta La traición de las imágenes, quizá su cuadro más famoso y que se caracteriza por representar, con el más nítido de los realismos, una pipa y colocar debajo la inscripción: "Ceci n'est pas une pipe". Con ello, Magritte evidencia que el arte es una máquina de ilusiones que no copia sino que inventa realidades, que busca alejarse del mundo aunque invariablemente remite a él y que tiene como única finalidad la articulación de un espejismo. Esa pipa que no lo es representa un claro ejemplo de que en el arte de vanguardia la paradoja ocupa un lugar central, debido a que constituye una figura de pensamiento y no sólo un recurso estético, hecho que la convierte en uno de los fundamentos estructurales de las obras. En el ámbito de la literatura, dicha simulación de algo que se niega aunque parezca estar ahí, funge como principio creativo en varias obras paradigmáticas de diversos géneros: Un coup de dés (1897), versos en los que Stéphane Mallarmé hizo del azar un elemento preciso en la poesía, Finnegans Wake (1939), novela sobre la marcha de James Joyce que consiste en una serie de innumerables fragmentos que esbozan una historia por demás confusa, y Sei personaggi in cerca d'Autore (1921), texto en el que Luigi Pirandello invita al público al estreno de un drama cuyos personajes esperan por su realización. Estos y muchos otros textos vanguardistas confirman que las obras literarias de dicho periodo encuentran su fuerza motriz en una espiral de paradojas y simulaciones, hacen del lector un cómplice en el juego del escondite, se burlan de la realidad y se muestran tan contradictorias como el ser humano.

Con todos los cambios que el vanguardismo llevó a cabo en la ontología de las obras, sería muy difícil pensar que esa actitud 
iconoclasta de reformular la estructura y el contenido discursivo terminó una vez superado el auge de dicho movimiento estético. Si bien las tres primeras décadas del siglo XX representan el lapso de mayor experimentación, el impulso vanguardista de jugar con el lenguaje y la materia artística persistió de diversas formas en expresiones ulteriores, ya que, una vez conquistadas la libertad creativa y el privilegio de lo imaginario, las artes se transformaron en espacios abiertos a la elaboración de las más caprichosas y sugerentes ideas sobre la existencia y el mundo. Una vez superada la efervescencia vanguardista, lo que persiste no son los denominados "movimientos históricos", sino el impulso experimental, el espíritu que libera al arte de la razón, el deseo de encontrar algo nuevo o de ver lo viejo con nuevos ojos, entre otras posturas cuyos orígenes están ligados a la revolución que implicó el estallido de las vanguardias. A propósito de la continuidad que tiene este periodo del arte, Renato Poggioli considera que

Si ha habido una superación, ésta ha consistido en la feliz transición de la vanguardia en sentido estricto a una vanguardia en sentido lato, en una derrota de la letra y una victoria del espíritu. La fiebre de otros tiempos está cediendo el paso a una lucidez controlada. A quien mire con ojos no enturbiados por ideologías partidistas, esta transición aparecerá como un patente progreso, mientras que a quien siga teniendo fe en una retórica que ya no es programática, y que la lección del tiempo está demostrando nociva, además de inútil, podrá parecerle un regreso o una reacción de retorno. La transición en curso está obrando una mutación, no una negación (2011: 224).

Lo que sí se perdió con el tiempo fue el carácter obligatorio que tenían la extrańeza, el rupturismo y la novedad, consignas creativas de la vanguardia que estuvieron muy relacionadas con ese interés de provocación social, con la actitud rebelde y combativa que 
mostraban los artistas. Cuando empieza a calmarse el fervor político-social que rodeaba al arte de vanguardia y sus innovaciones se convierten, irremediablemente, en lugares comunes, salen a flote las verdaderas consecuencias que el vanguardismo tuvo en relación con la estructura esencial de las obras, pues la independencia creativa, la búsqueda de originalidad, el albedrío de la imaginación y la posibilidad de crear algo imposible, dejan de ser aspectos de una moda artística y literaria para convertirse en piedra angular de lo que podría denominarse arte posmoderno. ${ }^{7}$ Entonces, más que estilos o movimientos identificables, el legado de las vanguardias al arte occidental consiste en que no sólo se cambió la manera de hacer las obras, sino toda la concepción que de ellas se tenía. No resulta muy descabellado afirmar que desde entonces a la actualidad las manifestaciones artísticas son tan diversas que tienen como únicos rasgos en común la libertad y la imaginación, pues en el arte posmoderno y contemporáneo las estructuras definidas por las tradiciones clásicas están ausentes o no son más que piezas de un todo fragmentario y mucho más complejo.

${ }^{7}$ A pesar de que tal término cuenta con diversas implicaciones de carácter histórico-sociológico, aquí se retoma únicamente como referente temporal que permite englobar la producción artística consecutiva a las vanguardias. Al respecto, el filósofo Jean Lyotard, en su obra La condición postmoderna. Informe sobre el saber (1984), afirma que dicho concepto: "Designa el estado de la cultura después de las transformaciones que han afectado a las reglas de juego de la ciencia, de la literatura y de las artes a partir del siglo XIX." (4). Sin embargo, el mismo Lyotard señala la imposibilidad de fijar el momento histórico en el que surge y el sentido preciso que adquiere el término, ya que: "el saber cambia de estatuto al mismo tiempo que las sociedades entran en la edad llamada postindustrial y las culturas en la edad llamada postmoderna. Este paso ha comenzado cuando menos desde fines de los años 50, que para Europa señalan el fin de su reconstrucción. Es más o menos rápido según los países, y en los países según los sectores de actividad: de ahí una discronía general que no permite fácilmente la visión de conjunto.” (6). 
Aunque la fugacidad fue otra característica de los movimientos de vanguardia, el rastro que dejaron parece perpetuo, pues hasta el momento no se ha registrado una revalorización ontológica de la obra tan compleja y profunda como la que tuvo lugar durante el vanguardismo. Los postulados estéticos que se derivan de dicho periodo del arte resultan trascendentes porque, además de modificar la constitución de las obras, también fracturaron el paradigma mimético-referencial que guiaba su decodificación. Por tanto, artistas y receptores tuvieron que olvidar lo aprendido y buscar un nuevo camino para la creación e interpretación de las obras. Es cierto que el rechazo de la realidad, las rupturas formales y la experimentación son actitudes que encuentran un precedente en la rebeldía e inquietud de los románticos, sin embargo, como señala Octavio Paz: "hay algo que distingue a los movimientos de vanguardia de los anteriores: la violencia de las actitudes y los programas, el radicalismo de las obras. La vanguardia es una exasperación y una exageración de las tendencias que la precedieron" (432), hecho que explica la notoria transformación que durante tal época tuvo tanto la idea del arte como las posibilidades de su elaboración. Describir minuciosamente las implicaciones de la estética vanguardista resulta una tarea irrealizable, prueba de ello es que estas reflexiones sobre el ensimismamiento, la deshumanización, la fragmentariedad, el shock, el humor y la paradoja apenas son suficientes para explicar que la naturaleza ontológica de los discursos fincados en el arte se transformó radicalmente durante los primeros años del siglo XX.

A manera de colofón, cabe mencionar que todas estas innovaciones respecto a la concepción y ejercicio de la literatura, aunque gestadas en el viejo continente, tuvieron rápida resonancia en las letras latinoamericanas, pues varios escritores y artistas se encargaron de propagar esta nueva estética por medio de manifiestos 
y de ejercerla a través de sus discursos ${ }^{8}$. En este punto es preciso aclarar que el vanguardismo hispanoamericano no debe ser visto como un epifenómeno de la vanguardia europea, ya que, aunque las líneas de relación entre uno y otro son indiscutibles, también es cierto que las manifestaciones vanguardistas en nuestro continente cuentan con su propio estilo, pues no son la aplicación de una estética extranjera, sino el resultado original de la manera en que los escritores latinoamericanos interpretaron el fenómeno de las vanguardias. Pero al margen de las diferencias, lo cierto es que varios autores latinoamericanos también ofrecieron al lector extraños discursos que desarrollaban el disparate, rompían todas las reglas de la escritura mimético-realista, reflexionaban en torno al artificio y la palabra y, lo primordial, evidenciaban que la esencia de la literatura había sufrido una radical transformación. Este cambio ontológico de la obra vanguardista puede observarse con claridad en ciertos textos latinoamericanos como Veinte poemas para ser leidos en el tranvía (1922) de Oliverio Girondo, Cosmogonía (1925) de Pablo de Rokha, "Novela guillotinada" (1927) de Pablo Palacio, los Papeles de recienvenido (1929) escritos por Macedonio Fernández, el Libro sin tapas (1929) de Felisberto Hernández, Altazor (1931) de Vicente Huidobro y la novela corta Un año (1935) de

${ }^{8}$ Una lectura general de los manifiestos latinoamericanos de vanguardia, por ejemplo los compilados por Nelson Osorio (Biblioteca de Ayacucho, 1980) o Jorge Schwartz (Fondo de Cultura Económica, 2002), muestra diversos ejes temáticos que aparecen de manera constante y que se relacionan con la revalorización ontológica de la obra vanguardista. Algunos de ellos son: el gusto desmedido por lo novedoso, el deseo de no ajustar el proceso creativo a regla alguna, el interés por vaciar las palabras de significado concreto, el tono humorístico de las consignas y la organización fragmentaria de los discursos. De esta forma, los manifiestos y textos programáticos de la vanguardia latinoamericana, al concentrarse en discutir las novedades literarias que venían de Europa, constituyen un amplio y diverso corpus que da cuenta de cómo fue asimilada esta transformación medular de la obra en nuestro continente. 
Juan Emar, por mencionar algunos títulos en los que, indiscutiblemente, se advierte que la literatura no fue la misma antes y después de las vanguardias.

\section{Bibliografía:}

Blanchot, Maurice, 2007, "Reflexiones sobre el surrealismo", en La parte del fuego, Isidro Herrera (trad.), Madrid, Arena Libros, pp. 83-93.

Bürger, Peter, 1987, Teoría de la vanguardia, Jorge García (trad.), Barcelona, Península.

De Micheli, Mario, 1984, Las vanguardias artísticas del siglo XX, Ángel Sánchez Gijón (trad.), Madrid, Alianza.

Enzensberger, Hans Magnus, 1963, "Las aporías de la vanguardia” Pablo Simon (trad.), Revista Sur, núm. 285, noviembre-diciembre, Buenos Aires, pp. 1-23.

Lyotard, Jean-François, 1984, La condición posmoderna. Informe sobre el saber, Mariano Antolin Rato (trad.), Madrid, Cátedra.

Mata, Rodolfo, 2011, "Prólogo" en Renato Poggioli, Teoría del arte de vanguardia, Rosa Chacel (trad.), México, UNAM, pp. I-XI.

Ortega y Gasset, José, 1995, “La deshumanización del arte” en El sentimiento estético de la vida: antología, Madrid, Tecnos, pp. 316-328.

Paz, Octavio, 1994, Los hijos del limo en La casa de la presencia. Obras completas 1, México, Fondo de Cultura Económica, pp. 321-484.

Piñón, Helio, 1987, "Prólogo" en Peter Bürger, Teoría de la vanguardia, Jorge García (trad.), Barcelona, Península, pp. 5-30. 
Poggioli, Renato, 2011, Teoría del arte de vanguardia, Rosa Chacel (trad.), México, UNAM.

Rubert de Ventós, Xavier, 1997, El arte ensimismado, Barcelona, Anagrama.

Schulte-Sasse, Jochen, 1989, "La vanguardia artística", publicado originalmente en la International Encyclepedia of Communications, Nueva York y Oxford, University Press, pp. 543-551, disponible en: http://www.uca.edu.sv/revistarealidad/archivo/4df 29f2013222lavanguardia.pdf, (consultado el: 21/III/2013).

Shklovski, Viktor, 2007, "El arte como artificio", en Tzvetan Todorov (comp.), Teoría de la literatura de los formalistas rusos, Ana María Nethol (trad.), México, Siglo XXI, pp. 55-70.

(Artículo recibido el 19 de septiembre de 2013; aceptado el 23 de octubre de 2013). 